\title{
Bipolar disorder with Melnick-Needles syndrome and periventricular nodular heterotopia: two case reports and a review of the literature
}

\author{
Maria Pia Riccio ${ }^{{ }^{* \dagger}}$, Giuseppe D’Andrea ${ }^{2 \dagger}$, Emilia Sarnataro ${ }^{1}$, Maria Marino ${ }^{1}$, Carmela Bravaccio ${ }^{1}$ and \\ Umberto Albert ${ }^{3}$
}

\begin{abstract}
Background: Melnick-Needles syndrome and periventricular nodular heterotopia are two usually mutually exclusive phenotypes of F-actin-binding cytoskeletal phosphoprotein Filamin-A mutations. Melnick-Needles syndrome is a rare $X$-linked condition that is lethal in males and shows great phenotypic variability in affected females. It is caused by mutations in Filamin-A gene, which encodes the protein Filamin A. Defects of the human Filamin-A gene also cause $X$-linked periventricular nodular heterotopia, a malformation of neuronal migration characterized by nodules of neurons in inappropriate location adjacent to the walls of the lateral ventricles.

Case presentation: We report on two Caucasian adolescent females, sisters, diagnosed with Melnick-Needles syndrome and bilateral periventricular nodular heterotopia, who developed bipolar disorder and somatic symptoms disorder at a young age. We also present a review of the literature about mental disorders associated with periventricular nodular heterotopia. Our report shows that patients presenting with atypical and heterogeneous psychiatric disease may have an underrecognized anatomical brain abnormality on genetic basis.

Conclusions: We found records of psychiatric disorders associated with periventricular nodular heterotopia; nevertheless, this is the first report of bipolar disorder occurring in individuals with periventricular nodular heterotopia, and the first report of any psychiatric disorder in individuals affected by Melnick-Needles syndrome. In conclusion, this case report may contribute to characterizing the phenotype of this very rare syndrome.
\end{abstract}

Keywords: Bipolar disorder, Melnick-Needles syndrome, Periventricular nodular heterotopias, Case report

\section{Background}

Melnick-Needles syndrome (MNS, OMIM 309350) is a rare $\mathrm{X}$-linked bone dysplasia, belonging to the otopalatodigital spectrum disorders (OPDSD), with fewer than 70 cases described in the literature (Orphanet

\footnotetext{
*Correspondence: piariccio@gmail.com

${ }^{\dagger}$ Maria Pia Riccio and Giuseppe D'Andrea contributed equally to the work

${ }^{1}$ Department of Medical and Translational Sciences, Child

Neuropsychiatry, Federico II University, Via Pansini 5, Naples, Italy

Full list of author information is available at the end of the article
}

Encyclopaedia, May 2015). MNS is essentially limited to females as, when it affects males, it is embryonically or perinatally lethal [1], but survival may be possible due to mosaicism [2]. MNS generally presents with short stature, craniofacial disproportion, prominent supraorbital ridge, exorbitism, oligohypodontia, and micrognathia. Conductive deafness (due to ossicular malformation) and hydronephrosis are also common. Mitral and tricuspid valve prolapse, bowel malrotation, and joint subluxation may be observed. Obstructive sleep apnea syndrome may occur due to mandibular hypoplasia. Complete original author(s) and the source, provide a link to the Creative Commons licence, and indicate if changes were made. The images or other third party material in this article are included in the article's Creative Commons licence, unless indicated otherwise in a credit line to the material. If material is not included in the article's Creative Commons licence and your intended use is not permitted by statutory regulation or exceeds the permitted use, you will need to obtain permission directly from the copyright holder. To view a copy of this licence, visit http://creativecommons.org/licenses/by/4.0/. The Creative Commons Public Domain Dedication waiver (http://creativeco mmons.org/publicdomain/zero/1.0/) applies to the data made available in this article, unless otherwise stated in a credit line to the data. 
atrioventricular canal, prune belly syndrome, and omphalocele have been reported in lethally affected males (Orphanet Encyclopaedia, May 2015).

MNS is caused by missense mutation in the gene that encodes the F-actin-binding cytoskeletal phosphoprotein Filamin A (FLNA), a widely expressed protein that interacts with integrin receptors, transmembrane proteins, and several signaling proteins [3]. These interactions are believed to integrate extracellular and cytoplasmic signals with cellular cytoskeleton rearrangements and membrane reshaping $[4,5]$ and, thus, to allow locomotion of many cell types, including neurons, as shown by the finding of high-level expression in the developing cortex [6].

Defects of the human Filamin-A gene also cause $\mathrm{X}$-linked periventricular nodular heterotopia $(\mathrm{PNH})$, a malformation of neuronal migration characterized by nodules of neurons in inappropriate location adjacent to the walls of the lateral ventricles, having failed to migrate away from the embryonic ventricular zone to the developing cerebral cortex $[7,8]$. FLNA mutations have been found in a large number of patients with bilateral and symmetrical $\mathrm{PNH}$ [7] and represent the main cause for established monogenic forms of $\mathrm{PNH}$ accounting for almost all familial X-linked presentations [6]. The most common presentations of PNH are focal seizure disorder, neurological deficits such as dyslexia, developmental delays, and stroke [6, 9-11]. A broad range of neuropsychiatric conditions has been found in patients with $\mathrm{PNH}$ independently from FLNA gene mutation and type of heterotopia [12].

We aim to describe the cases of two sisters diagnosed with MNS and bilateral PNH, who developed bipolar disorder and somatic symptoms disorder at a young age. We also present a review of the literature about mental disorders associated with $\mathrm{PNH}$. Our report shows that patients presenting with atypical and heterogeneous psychiatric disease may have an underrecognized anatomical brain abnormality on genetic basis. The finding of $\mathrm{PNH}$ on magnetic resonance imaging (MRI) of these patients may address more appropriate treatment. Moreover, to the best of our knowledge, this is the first report of psychiatric disease in patients affected by MNS and may contribute to characterizing the phenotype of this very rare syndrome.

\section{Case presentation}

We will describe the cases of two Caucasian females, sisters having a 4-year age difference, diagnosed with MNS and associated PNH, who both required child and adolescent psychiatry assistance at a young age, during adolescence.

The patients inherited from the mother the FLNA gene carrying a c.622G $>C$ nucleotide change, that leads to the aminoacidic substitution p.Gly208Arg in the N-terminal domain of Filamin A. The mother was affected as well by MNS, but, due to a milder phenotype, she was diagnosed only after her offspring received the diagnosis.

\section{Case 1}

At the age of 10 years old, the patient came to the attention of a specialized center owing to facial dysmorphism, prominent forehead and ears, bilateral exophthalmos, blue sclera, full cheeks, preauricular fistulas, dental malocclusion, skin dyschromia, valgus knees and elbows, and a history of hip subluxation and left-convex lumbar scoliosis. These findings were consistent with a possible congenital osteodysplasia; thus, she underwent full-body radiography. The radiography showed basicranium thickening, dorsolumbar kyphoscoliosis, bilateral coxa valga, and mild bowing of the radius in both sides. An MRI of the brain was performed, revealing bilateral nodules of periventricular heterotopia $(\mathrm{PH})$, arachnoid cyst of the medial temporal lobe, and volume loss in the hypophysis. She was then referred for genetic counseling: analysis of FLNA gene was made, and missense mutation G622C was identified in exon 3 of the gene, leading to diagnosis of MNS.

By the age of 14 years old, she presented with obsessions, repetitive behavior, and paranoid ideation. Later, she developed anxiety symptoms, panic attacks, and episodes of apparent loss of consciousness, accompanied by falls and abnormal movements of the limbs. For the repetitive occurrence of these convulsive-like phenomena, she was admitted to the Neurology Service, and an electroencephalogram (EEG) video study was performed. She was dismissed with the diagnosis of psychogenic non-epileptic seizures (PNES) and received a short treatment with delorazepam. After some months, she presented with a major depressive episode characterized by depressed mood, feelings of worthlessness, psychomotor agitation, social withdrawal, inability to concentrate in studies, and recurrent thoughts of death. For this clinical presentation, she was referred to a private practice psychiatrist and a few months later to an outpatient visit at our Child and Adolescent Neuropsychiatry Service. At the time of the first visit, she had already received treatment with different classes of psychotropic agents, including antipsychotics, antidepressants, and benzodiazepines. During the visit, she presented severe psychomotor agitation, talkativeness, pressured speech, and distractibility, and was referred for outpatient psychodiagnostic. Few weeks later, however, she was urgently admitted to our inpatient for a manic episode with anxiety and reoccurrence of PNES. At the time of admission, she had been prescribed paroxetine $20 \mathrm{mg}$ for a week; she showed emotional hyperreactivity, racing thoughts 
with derailment, unusual talkativeness and loud voice, disinhibited behavior, and inappropriate social interactions with medical staff. Her hemogram, thyroid, kidney and liver function test, and electrolytes were within normal limits. No alterations were found on EEG during sleep. Electrocardiography (EKG) showed right partial bundle branch block and sinus rhythm. Intelligence quotient (IQ) derived from administration of Wechsler Intelligence Scale for Children (WISC-IV) was 113. She was diagnosed with bipolar disorder and was prescribed valproic acid $900 \mathrm{mg} /$ day and very low dose of risperidone $0.5 \mathrm{mg} /$ day. Later, she was prescribed lithium carbonate at $600 \mathrm{mg} /$ day with good response. Growing up, the patient presented a good compensation for clinical symptoms, thanks to combination of pharmacological treatment and psychotherapy, which also allowed her to follow studies at the university and to lead an independent life.

\section{Case 2}

By the age of 9 years old, the second patient was admitted to inpatient unit of pediatric neurology owing to flaccid paraparesis of lower limbs, lasting 1 week, which was diagnosed as a somatic symptoms disorder. At the age of 10 years old, she underwent the same diagnostic workup as the first one, as she presented with similar clinical features. The diagnosis of MNS was confirmed by the finding of the missense mutation G622C in exon 3 of the FLNA gene. MRI brain scan showed frontoparietal PNH. At the age of 16 years, she was referred to a neuropsychiatric visit at our Child and Adolescent Psychiatry outpatient clinic owing to recurrent depressive episodes that compromised family, social, and school functioning. Full Scale IQ derived from administration of WISC-IV was 105. She presented with depressed mood and referred irritability, recurrent thoughts of death, anhedonia, and apathy. Mood was worse by the morning. She suffered with loss of appetite, fatigue, and central insomnia. She had quit school for a long period and showed difficulties in both concentrating and making decisions. She referred that the recurrent depressive episodes were interrupted by brief periods of elated mood, grandiosity, racing thoughts, increased talkativeness, and decreased need for sleep. She had never been prescribed any psychotropic medication before. She was diagnosed with bipolar disorder, and lithium carbonate was introduced and titrated up to $900 \mathrm{mg} /$ day. The following management of the mood disorder was compromised by lack of compliance to the treatment and adverse reactions to both lithium carbonate and sulfate administration; thus, she went on to develop a disorder with depressive predominant polarity, characterized by school and social withdrawal, and somatic symptoms.

\section{Discussion and conclusion}

MNS is a rare X-linked condition that is lethal in males and shows great phenotypic variability in affected females. It is caused by mutations in FNLA gene, which encodes the protein Filamin A. Overall, seven mutations have been found and involve exons 7, 22 (> 90\% of cases), and 28 [3, 13, 14]. Our patients exhibited a novel mutation, located in exon 3, which leads to p.Gly208Arg substitution in the calponin homology 2 domain of the actin-binding-domain (ABD) of Filamin A, in a highly evolutionarily conserved residue. This critical non-conservative mutation has been hypothesized to induce both missense substitution and aberrant messenger Ribonucleic Acid (mRNA) splicing, resulting respectively in lossof-function and gain-of-function of FLNA. This process is thought to have led to the exceptional co-occurrence of PNH (caused by FLNA loss-of-function) and MNS (caused by FLNA gain-of-function), two otherwise mutually exclusive allelic phenotypes [15].

We described the cases of two females affected by MNS and PNH who presented with psychiatric disorders at a young age and were later diagnosed with earlyonset bipolar disorder characterized by rapid cycling (not always drug-related), somatic symptoms disorder as epiphenomenon of the mood episode, and different response to mood stabilizers. Neuroimaging studies of subjects with early-onset bipolar disorder found brain anatomical abnormalities in the emotional control network (ECN), such as amygdala volume alterations, and abnormal white-matter microstructure in frontal regions, corpus callosum, and internal capsule, responsible for prefrontal-limbic dysfunctional connectivity [16]. There is no report of PNH associated with early-onset bipolar disorder; however, $\mathrm{PNH}$, especially when there is an underlying FLNA mutation, has been associated with multiple white-matter microstructure alterations, which may be undetectable on common MRI [17].

To date, psychiatric disorders have not been described in association with MNS; searching the literature, we found reports of 33 patients suffering from $\mathrm{PNH}$ and psychiatric disorders, mainly reported as single cases. The disorders diagnosed included: psychotic disorders $[7,12,18-26]$, depression $[12,27-29]$, anxiety $[23,30$, 31], obsessive-compulsive disorder [23, 32], neurodevelopmental disorders [12, 33, 34], and behavioral disorders [35-38]. Including our patients, there was slight prevalence of females $(n=22 ; 64.7 \%)$; mean age at onset of the psychiatric disorder was $26.3 \pm 14.2$ years, ranging from 8 to 53 years. Intelligence was normal for $40 \%$ of subjects $(n=14)$ and borderline for $14.3 \%(n=5)$, while the remaining individuals experienced mild-tosevere intellectual disability (ID). Epilepsy was associated with $\mathrm{PNH}$ in $54.3 \%$ of cases $(n=19)$, and additional 
MRI findings were reported in $40 \%$ of patients $(n=14)$. Underlying genetic mutations were found in $40 \%$ of cases $(n=14)$ : seven were mutations of FLNA (including our patients), and seven were 22q11.2 deletions. PNH varied from single nodules to bilateral contiguous deposits. Overall, PNH appears associated with a broad range of psychiatric disorders, whose onset presents mainly during adolescence or early adulthood. Additional pharmacologic therapy based on MRI findings may be required to treat the disorder $[12,39]$. These reports suggest a link between PNH and psychiatric disorders, but scientific evidence to confirm this association is lacking. Possibly, the neuropsychiatric manifestations result from abnormal brain development on genetic or environmental basis.

Patients with MNS do not usually have PNH, as FLNArelated PNH derives from a loss-of-function mutation, while MNS, as well as the others OPDSD, derives from a gain-of-function mutation of the FLNA gene [40]. The structure of FLNA protein and its interaction with actin and various membrane receptors is complex. Possible mutations of FLNA protein are various. This complexity reflects the wide spectrum of phenotypes. In the presented cases, a single mutational event leads to both the missense substitution and the aberrant mRNA splicing of FLNA protein. The c.622G $>$ C substitution caused an aberrant mRNA splicing and also leads to a missense mutation, resulting in loss-of-function of FLNA, associated with the PNH phenotype, and at the same time to a missense mutation, resulting in gain-of-function and in MNS.

Given that psychiatric diseases have not been described in association with MNS or with any of the OPDSDs, a major role in the observed psychiatric disturbances may have been played by bilateral $\mathrm{PNH}$, rather than by MNS per se. In this perspective, psychiatric disorders, more specifically bipolar disorder, may be part of the MNS phenotype when PNH is co-occurring, and thus, MRI scan should be performed in all patients with MNS to detect the possible coexistence of both phenotypes.

In conclusion, this is the first report of bipolar disorder in patients with MNS and PNH. Moreover, this is the first report of psychiatric disorder in a very rare syndrome such as MNS. How the psychiatric features are influenced by the underlying genetic cause of both MNS and PNH remains uncertain. Individuals affected may be at risk for early-onset psychiatric disorders, but further studies are needed to demonstrate the cause of this association. Clinicians should be aware that atypi$\mathrm{cal}$ and heterogeneous psychiatric disorders may be the consequence of an underrecognized anatomic abnormality relying on genetic cause; thus, appropriate diagnostic work-up, including neuroimaging, should be conducted.

\section{Abbreviations}

MNS: Melnick-Needles syndrome; PNH: Periventricular nodular heterotopia; FLNA: F-actin-binding cytoskeletal phosphoprotein Filamin A; OPDSD: Otopalatodigital spectrum disorders; MRI: Magnetic resonance imaging; $\mathrm{PH}$ : Periventricular heterotopias; EEG: Electroencephalogram; PNES: Psychogenic non-epileptic seizures; EKG: Electrocardiography; IQ: Intelligence quotient; WISC-IV: Wechsler Intelligence Scale for Children; ABD: Actin-binding domain; ECN: Emotional control network; ID: Intellectual disability; mRNA: messenger Ribonucleic Acid.

\section{Acknowledgements \\ No acknowledgements.}

\section{Authors' contributions}

MPR carried out one of the patient's clinical evaluations and wrote the work, GDA wrote the work and reviewed the literature, MM carried out psychodiagnostic evaluations and language editing, ES performed the clinical evaluations of one of the patients, CB corrected and supervised the work for the neurodevelopmental part, and UA corrected and supervised the work for the psychiatric part. All authors read and approved the final manuscript.

\section{Funding \\ No fund.}

\section{Availability of data and materials}

The datasets used and/or analyzed during the current study are available from the corresponding author on reasonable request.

\section{Declarations}

Ethics approval and consent to participate

Not applicable.

\section{Consent for publication}

Written informed consent was obtained from the patient's legal guardian for publication of this case report and any accompanying images. A copy of the written consent is available for review by the Editor-in-Chief of this journal.

\section{Competing interests}

The authors declare that they have no competing interests.

\section{Author details}

${ }^{1}$ Department of Medical and Translational Sciences, Child Neuropsychiatry, Federico II University, Via Pansini 5, Naples, Italy. ${ }^{2}$ Department of Biomedical and NeuroMotor Sciences (DIBINEM), University of Bologna, Bologna, Italy. ${ }^{3}$ Department of Medicine, Surgery, and Health, University of Trieste, Trieste, Italy.

Received: 23 June 2020 Accepted: 6 August 2021

Published online: 11 October 2021

\section{References}

1. Robertson SP. Otopalatodigital syndrome spectrum disorders: otopalatodigital syndrome types 1 and 2, frontometaphyseal dysplasia and Melnick-Needles syndrome. Eur J Hum Genet. 2007;15(1):3-9. https://doi. org/10.1038/sj.ejhg.5201654.

2. Guerrini R, Mei D, Sisodiya S, et al. Germline and mosaic mutations of FLN1 in men with periventricular heterotopia. Neurology. 2004;63(1):516. https://doi.org/10.1212/01.WNL.0000132818.84827.4D.

3. Robertson SP, Twigg SRF, Sutherland-Smith AJ, et al. Localized mutations in the gene encoding the cytoskeletal protein filamin A cause diverse malformations in humans. Nat Genet. 2003;33(4):487-91. https://doi.org/ 10.1038/ng1119.

4. Dulabon L, Olson EC, Taglienti MG, et al. Reelin binds a $3 \beta 1$ integrin and inhibits neuronal migration. Neuron. 2000;27(1):33-44. https://doi.org/10. 1016/S0896-6273(00)00007-6. 
5. Tu Y, Wu S, Shi X, Chen K, Wu C. Migfilin and Mig-2 link focal adhesions to filamin and the actin cytoskeleton and function in cell shape modulation. Cell. 2003;113(1):37-47. https://doi.org/10.1016/s0092-8674(03)00163-6.

6. Fox JW, Lamperti ED, Eks YZ, et al. Mutations in filamin 1 prevent migration of cerebral cortical neurons in human periventricular heterotopia. Neuron. 1998;21:1315-25. https://doi.org/10.1016/S0896-6273(00) 80651-0.

7. Parrini E, Ramazzotti A, Dobyns WB, et al. Periventricular heterotopia: phenotypic heterogeneity and correlation with Filamin A mutations. Brain. 2006;129(7):1892-906. https://doi.org/10.1093/brain/awl125.

8. Battaglia G, Chiapparini L, Franceschetti S, et al. Periventricular nodular heterotopia: classification, epileptic history, and genesis of epileptic discharges. Epilepsia. 2006;47(1):86-97. https://doi.org/10.1038/modpa thol.3800179

9. Chang BS, Ly J, Appignani B, et al. Reading impairment in the neuronal migration disorder of periventricular nodular heterotopia. Neurology. 2005;64(5):799-803. https://doi.org/10.1212/01.WNL.0000152874.57180 AF.

10. Guerrini R, Carrozzo R. Epileptogenic brain malformations: clinical presentation, malformative patterns and indications for genetic testing. Seizure. 2002;11:532-47. https://doi.org/10.1053/seiz.2001.0650.

11. Barkovich AJ, Guerrini R, Kuzniecky RI, Jackson GD, Dobyns WB. A developmental and genetic classification for malformations of cortical development: update 2012. Brain. 2012;135(5):1348-69. https://doi.org/ 10.1093/brain/aws019.

12. Fry AE, Kerr MP, Gibbon F, et al. Neuropsychiatric disease in patients with periventricular heterotopia. J Neuropsychiatry Clin Neurosci. 2013;25(1):26-31. https://doi.org/10.1176/appi.neuropsych.11110336.

13. Foley C, Roberts $K$, Tchrakian N, et al. Expansion of the spectrum of FLNA mutations associated with Melnick-Needles syndrome. Mol Syndromol. 2010:1(3):121-6. https://doi.org/10.1159/000320184.

14. Santos HH, Garcia PP, Pereira L, et al. Mutational analysis of two boys with the severe perinatally lethal Melnick-Needles syndrome. Am J Med Genet Part A. 2010;152A(3):726-31. https://doi.org/10.1002/ajmg.a.33260.

15. Parrini $E$, Mei D, Pisanti MA, et al. Familial periventricular nodular heterotopia, epilepsy and Melnick-Needles Syndrome caused by a single FLNA mutation with combined gain-of-function and loss-of-function effects. J Med Genet. 2015;52(6):405-12. https://doi.org/10.1136/jmedg enet-2014-102959.

16. Goldstein Bl, Birmaher B, Carlson GA, et al. The International Society for Bipolar Disorders Task Force report on pediatric bipolar disorder: knowledge to date and directions for future research. Bipolar Disord. 2017;19(7):524-43. https://doi.org/10.1111/bdi.12556.

17. Liu W, An D, Niu R, Gong Q, Zhou D. Integrity of the corpus callosum in patients with periventricular nodular heterotopia related epilepsy by FLNA mutation. Neurolmage Clin. 2018;17:109-14. https://doi.org/10. 1016/j.nicl.2017.10.002.

18. Alexander RC, Patkar AA, Lapointe JS, Flynn SW, Honer WG. Schizencephaly associated with psychosis. J Neurol Neurosurg Psychiatry. 1997;63(3):373-5. https://doi.org/10.1136/JNNP.63.3.373.

19. Sener RN. Cerebellar vermian clefts disconnecting the hemispheres: a different entity unassociated with Joubert's syndrome. Comput Med Imaging Graph. 1997;21 (1):71-5. https://doi.org/10.1016/S0895-6111(96) 00068-7.

20. Pridmore S, Mclnerney G, Rybak M, Archer S. Psychotic disorder NOS with heterotopia. J Psychiatr Intensive Care. 2006;2(02):1 18. https://doi.org/10. 1017/S1742646407000386.

21. Kiehl TR, Chow EWC, Mikulis DJ, George SR, Bassett AS. Neuropathologic features in adults with 22q11.2 deletion syndrome. Cereb Cortex. 2009;19(1):153-64. https://doi.org/10.1093/cercor/bhn066.

22. Nopoulos PC, Flaum M, Andreasen NC, Swayze VW. Gray matter heterotopias in schizophrenia. Psychiatry Res Neuroimaging. 1995;61(1):11-4. https://doi.org/10.1016/0925-4927(95)02573-G.
23. Rezazadeh A, Bercovici E, Kiehl T-R, et al. Periventricular nodular heterotopia in 22q11.2 deletion and frontal lobe migration. Ann Clin Transl Neurol. 2018:5(11):1314-22. https://doi.org/10.1002/acn3.641.

24. Oshikubo G, Tochigi M, Akahane A, Hayashi N, Ikebuchi E. Graves' hyperthyroidism-induced psychosis in a patient with periventricular nodular heterotopia. Psychiatry Clin Neurosci. 2015;69(8):505-6. https:// doi.org/10.1111/pcn.12309.

25. Patel R, Stuarta KM, Nmbudiri D. Improved treatment acceptance and adherence following the diagnosis of multiple malformations of cortical development in a patient with psychosis. Brain Disord Ther. 2015. https:// doi.org/10.4172/2168-975X.1000192.

26. Takuya U, Mikio H, Itaru M, et al. A case of schizophrenia with gray-matter heterotopias. Fukushima Med J. 2003;53:265-9.

27. Kandemir M, Pelin Z, Kucukali C, Yilmaz N. A case with bilateral periventricular nodular heterotopia diagnosed as depression. Turk Noroloji Dergisi. 2010;16:114-8.

28. Sheen VL, Basel-Vanagaite L, Goodman JR, et al. Etiological heterogeneity of familial periventricular heterotopia and hydrocephalus. Brain Dev. 2004;26(5):326-34. https://doi.org/10.1016/j.braindev.2003.09.004.

29. Maruyama Y, Onishi H, Miura T, Kosaka K. A case of depressive disorder with neuronal heterotopia. Psychiatry Clin Neurosci. 1998;52(3):361-2. https://doi.org/10.1046/j.1440-1819.1998.00385.x.

30. Ünal A, Saygi S. Clinical features, EEG findings and outcome in patients with bilateral periventricular nodular heterotopia and epilepsy. Turkish Med Sci. 2007:37:157-65.

31. Pop L, Popa I, Bacos IC, et al. 15 year-old girl with paresthesia, headache, and abdominal pain. Jurnalul Pediatrului 2007;10:32-5.

32. Yankovsky AE, Veilleux M, Dubeau F, Andermann F. Post-ictal rage and aggression: a video-EEG study. Epileptic Disord. 2005;7(2):143-7.

33. Wegiel J, Kuchna I, Nowicki K, et al. The neuropathology of autism: defects of neurogenesis and neuronal migration, and dysplastic changes. Acta Neuropathol. 2010;119(6):755-70. https://doi.org/10.1007/ s00401-010-0655-4.

34. Nopoulos P, Berg S, Castellenos FX, Delgado A, Andreasen NC, Rapoport $J$. Developmental brain anomalies in children with attention-deficit hyperactivity disorder. J Child Neurol. 2000;15(2):102-8. https://doi.org/ 10.1177/088307380001500208.

35. d'Orsi G, Tinuper P, Bisulli F, et al. Clinical features and long term outcome of epilepsy in periventricular nodular heterotopia. Simple compared with plus forms. J Neurol Neurosurg Psychiatry. 2004;75(6):873-8.

36. Cho WH, Seidenwurm D, Barkovich AJ. Adult-onset neurologic dysfunction associated with cortical malformations. AJNR Am J Neuroradiol. 1999;20(6):1037-43

37. Lin J, Peruchi MM, Masruha MR, Pacheco JP, Vilanova LCP. Self-aggression and congenital clubfoot: additional features to the septo-optic dysplasia complex. Arq Neuropsiquiatr. 2009;67(2A):299-301.

38. Ezura M, Kakisaka Y, Jin K, et al. A case of focal epilepsy manifesting multiple psychiatric auras. Brain Nerve. 2015;67(1):105-9. https://doi.org/10. 11477/mf.1416200093.

39. Bourgeois JA, Nisenbaum J, Drexler KG, Dobbins KM, Hall MJ. A case of subcortical grey matter heterotopia presenting as bipolar disorder. Compr Psychiatry. 1992;33(6):407-10.

40. Clark AR, Sawyer GM, Robertson SP, Sutherland-Smith AJ. Skeletal dysplasias due to filamin A mutations result from a gain-of-function mechanism distinct from allelic neurological disorders. Hum Mol Genet. 2009;18(24):4791-800. https://doi.org/10.1093/hmg/ddp442.

\section{Publisher's Note}

Springer Nature remains neutral with regard to jurisdictional claims in published maps and institutional affiliations. 